\title{
El extraño caso del detective que volvió de su propia muerte
}

\author{
Claudia TaPia VÁsQuez \\ Universidad Católica de Chile \\ ctapia@ucsc.cl
}

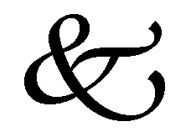

\begin{abstract}
Resumen
Desde 1841, el investigador privado, personaje que conecta el género policial con la actividad intelectual y crítica, se regenera en las más caleidoscópicas versiones. Este trabajo apunta precisamente a reconocer que tras la muerte de Erik Lönnrot, en "La muerte y la brújula”, el detective resucita en Emilio Renzi, de "La loca y el relato del crimen". Ese tránsito da cuenta de la transformación de un modelo reflexivo latinoamericano, propio de una cultura letrada, dirigida por hombres de excepción que confían en el poder y la centralidad de la palabra, a uno donde el avance de la globalización y los medios de masas han menoscabado el imperio de las letras, a cargo ahora de profesionales que habitan en las antípodas de la "ciudad ilustrada", limitados por la especialización y la institucionalización.
\end{abstract}

Palabras claves: Género policial, detective, intelectual, crítico, Jorge Luis Borges, Ricardo Piglia.

\begin{abstract}
Since 1841 , the private investigator, character that connects the police procedural with the intellectual and critical activity, is regenerated in the most kaleidoscopic versions. This work precisely points to recognize that behind the death of Erik Lönnrot, in "Death and the Compass" (original Spanish title: "La muerte y la brújula"), the detective resurrects in Emilio Renzi, from "The Madwoman and the Story of a Crime" (original Spanish title: "La Loca y el relato del crimen"). This transition accounts for the transformation of a Latin-American reflexive model, proper to a literate culture, led by exceptional men that trust in the power and
\end{abstract}


centrality of words, to one where the advancement of globalization and mass media have undermined the empire of letters, now in charge of professionals who inhabit the antipodes of the "illustrated city", limited by the specialization and the institutionalization.

Keywords: Crime story, Detective, Intellectual, Critical, Jorge Luis Borges, Ricardo Piglia.

Recibido: 12/8/14 Aceptado: 1/10/14 Publicado on line: 10/2/15

En abril de 1841, el joven editor del Graham 's Magazine de Filadelfia, Edgar Allan Poe (1809-1849), publicó en sus páginas lo que era un relato más de aquel incipiente periodismo que no distinguía entre noticias y literatura. Pero "Los crímenes de la calle Morgue" fue una verdadera fundación, la primera de la serie de narraciones que conocemos como género policial y que lejos de las sentencias que lo degradan como una manifestación literaria menor, conecta con las expresiones paradigmáticas de una alta cultura: la lectura, la reflexión social y la crítica.

Es verdad que la serie tiene su punto de partida en un hecho marginal y rudimentario: el delito. Se trata de la ruptura del contrato social por el cual el ciudadano acepta las leyes de la sociedad, los derechos que ésta le resguarda y también las responsabilidades y castigos que conlleva su incumplimiento. El asesino o delincuente quebranta ese pacto y provoca una grieta en el orden del espacio compartido, con lo que se vuelve un enemigo de la comunidad, en realidad algo peor que eso dice Foucault: un monstruo que asesta sus golpes desde el interior mismo del conglomerado. El filósofo francés agrega que se trata de un sujeto "portador de un fragmento salvaje de naturaleza ${ }^{1} ;(\ldots)$ el malvado, el traidor, el loco quizá, el enfermo y pronto el anormal” (2008: 117).

La narrativa policial, por tanto, ficcionaliza uno de los hechos cruciales de la experiencia social. Ricardo Piglia dice que el género recrea el "elemento de pesadilla" que introduce el crimen en lo comunitario. Sigmund Kracauer (2010), por su parte, sostiene que muestra el rostro mismo de la sociedad, uno mucho más real del que pueden exponer otras manifestaciones artísticas:

Así como el detective descubre el secreto oculto entre los hombres, la novela policial revela, a través del médium estético, el misterio de la sociedad (...) Su estructura artística transforma la vida que resulta incomprensible en una traducción comprensible vertida sobre la auténtica realidad (41).

Para este pensador alemán el crimen se asocia a lo real, a la experiencia, a lo observable, a una "esfera inferior" respecto de los espacios donde moran

1 Poe ficcionalizó la idea en "Los crímenes de la calle Morgue" donde el asesino es un animal, casi un monstruo, un "otro" radical del hombre social. 
las ideas superiores. Su registro ficcional, por tanto, presenta siempre algo deformado y torcido, muy distinto a lo perfecto/superior:

Cuanto más profunda es la caída de la vida (el delito, lo bajo, lo irracional) tanto más necesita de la vida la obra de arte, que desmorona su existencia cerrada y reordena sus elementos (...) (2010: 39).

El asesinato, así perfilado, conlleva un enigma, que puede ser la autoría, los motivos o el modus operandi. El misterio es precisamente el factor que vincula el género con las potencias superiores del ser humano. Es que frente a lo desconocido se instala el intento de esclarecimiento, personificado en el detective que iniciará la ruta de investigación para descubrir la verdad oculta.

(...) el misterio caracteriza a la novela policíaca (...) Misterio. Investigación. He aquí los dos elementos esenciales cuya fusión, siempre laboriosa, siempre incompleta ha dado origen a este género extraño (Narcejac, 1970: 51)

Aplicando las categorías de Kracauer, el género moviliza entonces un acto visceral, producto de una pulsión primitiva, propio del campo sensitivo, que trata de ser resuelto por un detective que despliega en esa acción sus capacidades intelectivas y cerebrales. Son las dos dimensiones antinómicas de la serie que logran reconciliarse en él:

Sus ingredientes básicos: el misterio imaginado en función de la investigación que debía aclararlo. Misterio pensado en función de la investigación. El misterio consistía obligatoriamente en algún tenebroso crimen: arrastraba tras de sí todas las convenciones de la literatura más decididamente popular. La investigación, por el contrario, valorizaba los mecanismos más aristocráticos del esprit. La deducción aparecía siempre como la ambiciosa voluntad de la inteligencia que pretendía prescindir de la experiencia. Así, desde su nacimiento, la novela policíaca debía conjugar un folletín y un problema, hacer vibrar los nervios y captar, a la vez, la atención más exigente. Visceral y cerebral al mismo tiempo, no tenía tiempo de hablar al corazón, de mostrar personajes reales (...) la mueve una certeza: el razonamiento tendrá, siempre y en todas partes, la última palabra. (Narcejac, 1970: 53)

Estructuralmente esta simbiosis adoptaría la forma propuesta por Tzvetan Todorov. En su artículo "Los dos principios del relato" (1996) sostiene que la novela de crímenes se construye sobre la base de la relación problemática de dos historias: una ausente, la del crimen, y otra presente, la de la investigación, cuyo único propósito es sacar el velo de la primera.

La ficcionalización del delito y la pesquisa a partir de la constitución de la gran ciudad convierte a la literatura policial en el lugar de discusión de la sociedad y al detective en el intelectual dedicado a reflexionar, comprender y expresar los mecanismos de su funcionamiento, alguien que se enfrenta al problema del saber, la verdad y la justicia. Es quien pone en juego la capacidad de comprender los signos sociales, "es el que sabe leer en los rastros, como 
en un texto, verdades que están escondidas y, al mismo tiempo, es el gran intérprete" (Piglia, 2010).

A partir de la complejización de las relaciones comunitarias que gatilla la gran ciudad, el detective/intelectual comprenderá que la infracción a la ley, en sus variadas manifestaciones, ya no será un simple accidente social, sino un atributo componente. Al preguntarse por la popularidad del género, Bertolt Brecht (Link, 2003) responde que las experiencias vitales han acabado por adquirir un matiz catastrófico, lo que constituye el punto de inicio para aprehender el funcionamiento de la vida social. Detrás de las catástrofes, agrega, se asoma la sospecha de que alguien es el culpable, momento en que "el espíritu sale de patrulla", búsqueda que en las narraciones policiales se actualiza en el investigador privado.

El concepto de intelectual que propone Edward Said es (2007), en efecto, muy semejante al perfil del detective literario. Dice que se trata de un francotirador, amateur y perturbador, en permanente oposición al statu quo y en búsqueda de la independencia frente a las presiones. Ricardo Piglia, por su parte, sostiene que el investigador privado es una figura que se ha construido en torno al célibe solitario que no se vincula al cuerpo social, un hombre aficionado a resolver misterios policiales sólo "por amor al arte". La soltería sería la cifra de una libertad y autonomía que lo desconectan de cualquier institución, incluso de la más minúscula. En Formas Breves (2005b), el escritor argentino se pregunta desde qué lugar se puede juzgar a una sociedad en permanente delito:

(...) el detective, aunque forme parte del universo que analiza, puede interpretarlo porque no tiene relación con ninguna institución, ni siquiera con el matrimonio (...) porque ahí donde quede incluido no podrá decir lo que tiene que decir, no podrá ver, no tendrá la distancia suficiente para percibir las tensiones sociales (67)

Según Said sólo en esas condiciones el intelectual podrá ser "el autor de un lenguaje que se esfuerza por decirle la verdad al poder” (2007: 17)

El intelectual es un individuo con un papel público específico en la sociedad que no puede limitarse a ser un simple profesional sin rostro. Para mí el hecho decisivo es que el intelectual es un individuo dotado de la facultad de representar, encarnar y articular un mensaje, una visión, una actitud, una filosofía, una opinión para y a favor de un público (...) actuar como alguien a quien ni los gobiernos ni otras instituciones pueden domesticar fácilmente y cuya raison d'être consiste en representar a todas esas personas y cuestiones que, por rutina, quedan en el olvido o se mantienen ocultas (2007: 30)

Es precisamente la lengua, dice Said, el principal vehículo de la actividad reflexiva. De ahí que la capacidad de representar a través de su uso correcto sea una de las potencias más importantes a la hora de ofrecer visiones 
desenmascaradoras o alternativas para expresar la verdad. Eso implica hacer gala de sentido crítico, no aceptar fórmulas fáciles, relacionarse con las situaciones como contingentes y no como inevitables, concebirlas como producto de opciones históricas y sociales y no como realidades naturales o irreversibles.

De acuerdo a lo anterior, el intelectual será la voz de los que no tienen acceso al poder, al discurso. Por ello, él también pertenecería a la alteridad, a las minorías y las culturas marginadas. "(...) debe estar en el mismo barco que el débil y el no representado", asegura Said, pero nunca tanto como para no poder hablarle al poderoso: ni completamente integrado, ni plenamente exiliado, "adepto por mímesis pero también paria en secreto".

Por último, concluye el autor palestino, quien reflexione sobre la sociedad no debe concebir la tarea reflexiva como el producto de un reducido grupo de reyes-filósofos superdotados y moralmente capacitados que constituyan la conciencia de la humanidad. Por el contrario, tendrá que ser alguien que realice funciones concretas en los campos relacionados con la producción y distribución de conocimiento (profesor, periodista, escritor, sociólogo, artista, etc. $)^{2}$. Es decir, un hombre de acción, que se hace en la vida misma.

A ese segundo grupo adhiere el intelectual de compromiso, figura que el creador del género policial, Edgar Allan Poe, perfiló en el cuento inaugural de la serie. Allí, el chevalier Charles Auguste Dupin es el hombre culto y distinguido que resuelve acertijos policiales "solo por amor al arte", pero que al mismo tiempo se interna en el bajo mundo del crimen y del delito para encontrarse ahí con lo más despreciable de la sociedad. Ello figura a un detective/intelectual que oficia como el mediador entre la élite y la masa, el que liga las expresiones de la alta y la baja cultura. El propio Poe era el punto de intersección entre las tradiciones literarias refinadas, signos de prestigio, y las manifestaciones bastardas de una sociedad sin delicadezas. El género policial es por tanto el comentario implícito de una práctica que vincula al pensador, el hermeneuta o el crítico con el hombre/mujer de acción, que está en la vida misma, comprometido con la experiencia de sus pares.

Esa capacidad de estar siempre "entre" se ficcionaliza en la permanente tensión que moviliza al detective desde la institución policial hasta la institución criminal. Por una parte, se asocia efectivamente a "lo policial" como investigador, pero mantiene distancia del cuerpo institucionalizado, no asimilándose de este modo a la ley en sentido oficial. Por otra, sostiene relaciones con el mundo del delito sin ser un delincuente. Es decir, el detective

2 Michel Foucault distingue entre el intelectual universal, tipo Sartre, y el "específico", aquel que trabajando en una disciplina determinada, es capaz de utilizar su competencia en cualquier otro campo. 
tiene formas y figuras que lo asocian al orden establecido y, a su vez, al universo del bajo mundo, del fondo, estableciendo con ello una relación entre los dos elementos que el género, en cierto sentido, discute: la ley y la verdad.

\section{Detective, intelectual y crítico}

La simbiosis entre el detective literario y el intelectual conecta el género policial con la dimensión reflexiva del ser humano a través de un factor determinante: la lectura superior. El primero lee la escena del crimen y las pistas que encuentra en su investigación; el segundo lee los signos de la sociedad para comprenderla. "El acto de leer constituye al sujeto de la verdad", dice Piglia (2005a: 86).

El modelo está en la primera narración de la serie. Instalado en la librería de la rue Montmartre el chevalier Charles Auguste Dupin encuentra en la revisión de selectos libros y de periódicos masivos los suministros para su trabajo hermenéutico. Ese carácter bibliográfico hace que el detective sea el registro ficcional del crítico literario que persigue sobre la superficie de los textos las huellas que permiten descifrar el sentido de la obra. "La lectura de indicios realizada por el detective es posible porque ha sido precedida por una escritura -de la que sólo quedan algunos rastros- realizada por el criminal" (Parodi, 2011).

La propuesta procede de De Quincey y aparece en Chesterton. Ricardo Piglia la sostiene en varios de sus relatos. Dice en Crítica y ficción (1986):

La representación paranoica del escritor como delincuente que borra sus huellas y cifra sus crímenes perseguido por el crítico, descifrador de enigmas (...) Dupin es un gran lector, un hombre de letras, el modelo del crítico literario trasladado al mundo del delito. Dupin trabaja con el complot, la sospecha, la doble vida, la conspiración, el secreto: todas las representaciones alucinantes y persecutorias que el escritor se hace del mundo literario con sus rivales y sus cómplices, sus sociedades secretas y sus espías, con sus envidias, sus enemistades y sus robos (15).

Alejo Carpentier (Barili, 1999) problematiza la relación. En el ensayo "Apología de la novela policíaca" sostiene que el detective es al delincuente lo que el crítico de arte es al artista: mientras el primero explica, el segundo inventa. El criminal aparece como elemento creador, cuyo acto altera un equilibrio preestablecido y que equivale, por tanto, a la invención de un problema. Frente a éste, el investigador no tiene ningún margen para la creación, y sólo le queda explicar el mecanismo si acierta en su tarea investigadora. Es lo que Chesterton condensa en The Blue Cross: "The criminal is the creative artist; the detective only the critic".

Se trata de la lucha permanente entre quien comete el delito y su perseguidor, factores antinómicos que conforman los binomios en los que descansa 
gran parte de nuestra estructura social, que enfrenta a un elemento normalizado, central y dominante con otro indócil, resistente y oprimido.

El desarrollo histórico del género da cuenta de este enfrentamiento en términos bastante disímiles. En el policial clásico, de enigma o misterio, y que nace a mediados del siglo XIX, el crimen se concibe como un desafío a la razón humana y su resolución "aparece como un modelo epistemológico experimentable en toda la gama de las exploraciones del intelecto" (Parodi, 2011), un ejercicio bajo el influjo de lo que Piglia llama el "fetiche de la inteligencia pura". Aquí la comprensión del acertijo policial se hace bajo las coordenadas de la lucidez y la razón. Por ello, dice Facundo Gustavo Boccardi (2008), el género constituye al detective como el héroe de la modernidad, que emprende una aventura que lo llevará a develar el enigma, cifra del sentido oculto de la experiencia del ser humano, que se esconde tras las huellassíntomas.

El hard boiled, thriller, o policial negro es, por su parte, una narración drásticamente realista, que da cuenta del lado oscuro y podrido del mundo, donde conviven la violencia, corrupción, prevaricación, soborno o prostitución. Aquí, el asesinato referido en la diégesis es figura del crimen social. Ya no se abrazará la razón y la lógica deducción para resolver el caso. Más bien se avanza en su búsqueda a partir de la acción y el ritmo de los acontecimientos, en los que incluso puede intervenir el azar. A tal nivel que el detective puede ser un verdadero loser.

(...) en la novela negra no parece haber otro criterio de verdad que la experiencia: el investigador se lanza, ciegamente, al encuentro de los hechos, se deja llevar por los acontecimientos y su investigación produce fatalmente nuevos crímenes: una cadena de acontecimientos cuyo efecto es el descubrimiento. (Piglia, 1986: 60)

\section{Borges y el cazador cazado}

En 1935, Jorge Luis Borges publica Historia universal de la infamia, texto que según algunos estudiosos constituye el gesto inaugural de una tradición que hará convivir los géneros masivos y populares, materiales de una literatura menor y marginal como la narrativa policial, con manifestaciones literarias cultas. Admirador de G.K. Chesterton, y principalmente de Edgar Allan Poe (el hombre-genio), Borges será un antologador, crítico y escritor de policiales. Los seis problemas para don Isidro Parodi, "El jardín de los senderos que se bifurcan" y "La muerte y la brújula" son sus narraciones detectivescas.

Si acogemos la veneración de Borges por el policial clásico expuesta en "El cuento policial" (1997), donde asegura que este tipo de narración salva el orden en una época de desorden, y que su detective modelo es un "orgullo de 
la inteligencia”, se puede postular que "La muerte y la brújula” (2008) adhiere a los cánones del enigma. Sin embargo, al poco leer cualquier lectura previa se cancela y el relato se percibe desplazado, manejado sin superstición y con irreverencia, muy en sintonía con el plan literario de "El escritor argentino y la tradición”. En el análisis del texto hecho por Amelia Barili (1999), se destaca:

Con este cuento, Borges, lector de cuentos policiales, se instala en la tradición de ese género desarrollado por británicos y estadounidenses, maneja audazmente el legado recibido y revierte las convenciones del género en clara afirmación de su identidad como escritor latinoamericano (188)

Borges pone en acción al detective Erik Lönnrot que intenta descifrar "la secreta morfología de la malvada serie", una seguidilla de tres crímenes, con la confianza plena en la resolución del caso. Porque Lönnrot "se creía un puro razonador, un Auguste Dupin (...)", un detective que adhiere a un mundo que puede explicarse por sus relaciones lógicas y no por las hipótesis del comisario Trevinarus, en las que "interviene copiosamente el azar". "Bruscamente bibliófilo”, Lönnrot sólo cree en lo que lee, dice Ricardo Piglia, y por ello actúa en la escena del crimen como un erudito al que sólo le interesan los indicios textuales, indiferente a la realidad que puede aportar "nombres, arrestos, caras, trámites judiciales y carcelarios".

Por eso las hipótesis del investigador se tejen con los datos de los libros. Para él, la clave de la muerte del heresiólogo Marcelo Yarmolinsky no está en los zafiros del Tetrarca, sino las "Obras Completas" de la víctima. Mientras el comisario Trevinarus examina "una brusca estrella de sangre", los restos de cigarrillos de marca húngara e interroga a los contradictorios testigos del posible secuestro de Ginzberg, el detective, sin sacarse el sombrero, lee un libro en latín:

Erik Lönnrot sonrió y le leyó con toda gravedad un pasaje (que estaba subrayado) de la disertación trigésima tercera del Philologus: Dies Judaeorum incipit a solis occasu usque ad solis occasum diei sequentis. Esto quiere decir -agregó-: El día hebreo empieza al anochecer y dura hasta el siguiente anochecer (162).

Lönnrot es un convencido de que los hechos responden a un modelo textual, y por ello lee cartas, libros en octavo mayor, manuscritos, periódicos, planos y una "polvorienta palabra griega". Él se desenvuelve como un crítico.

Pero algo de aventurero había él, "y hasta de tahúr". Es que en el cuento de Borges el detective no descubre la verdad, a lo más prevé el último asesinato, pero no logra impedirlo. Esa muerte es la de Erik Lönnrot. El infalible Dupin tiene aquí un heredero frustrado: a pesar que dibuja con erudición el mapa intelectual con el que resolverá el enigma, su descubrimiento sólo es un gesto, pues nunca se da cuenta que todo el tiempo se dirigió al abismo, siguiendo una 
ruta ideada por otro lector, el asesino Scharlach, hambriento de venganza. En "La muerte y la brújula" el detective muere y gana el criminal.

Pero Borges introduce otra variación del género. Para el policial clásico, las hipótesis elaboradas por el investigador privado llevan finalmente a la verdad, mientras que la policía se pierde en pistas falsas, líneas de investigación demasiado previsibles, clichés, conjeturas prosaicas y confusas teorías. Aquí, en cambio, el prefecto Franz Treviranus demuestra oficio y olfato. Se trata del funcionario pragmático que persigue los resultados y que no tiene "tiempo que perder en supersticiones judías". Con mal humor le responde a un lógico Lönnrot:

No me interesan las explicaciones rabínicas; me interesa la captura del hombre que apuñaló a este desconocido (157).

Y a la larga, las improvisadas, poco interesantes e imaginarias hipótesis del policía, serán un acierto.

Con estas subversiones, Borges deja al final del cuento a un detective inestable, en completa vulnerabilidad: mientras creía interpretar correctamente las claves textuales para explicar la serie de asesinatos, era el personaje inconsciente de una tragedia escrita por el homicida; mientras creía actuar libremente estaba comportándose según las leyes de un relato proyectado por otra mente. Y si el criminal maniobra los hilos de su perseguidor, éste será un cazador cazado.

Sin Lönnrot ¿quién descubrirá al asesino?, ¿o el crimen copará la escena de la ciudad? Un dato del cuento puede llenar el vacío: instalado en la escena de investigación también está el periodista de la Yidische Zaitung, quien en su búsqueda incluso entrevista al detective, pero mientras él inquiere información sobre el asesinato, el segundo prefiere hablar de los diversos nombres de Dios. En "La muerte y la brújula", a diferencia de los cuentos inaugurales del género, donde los medios sólo aportan suministros para el desciframiento del enigma, el detective convive con un sistema de prensa que interpreta la realidad que informa, un periodismo crítico y analítico. $\mathrm{La}$ Cruz de la Espada, El Mártir, la Yidische Zaitung contrastan y reprueban el rumbo de la investigación policial.

Muerto Lönnrot, entonces, la resolución del caso bien podría quedar en manos del redactor "miope, ateo y muy tímido". La descripción parece una imagen especular del propio Borges quien, cabe recordar, colaboró en el diario Crítica, en el suplemento multicolor de los sábados. Se trata, según Beatriz Sarlo (2007) del encuentro de un escritor de la elite con el diario de masas que había inaugurado el periodismo sensacionalista en Argentina. Borges se comporta como el mediador entre la alta y la baja cultura, un intelectual que se desenvuelve cruzando los diversos discursos literarios, mezclando las operaciones más complicadas de la literatura mayor con los géneros menores; 
y también alterando las formas del discurso periodístico y sus modalidades tradicionales de inserción y recepción.

¿El reportero en vez del detective? ${ }^{3}$.

\section{Piglia, la loca y el relato del periodista}

Ricardo Piglia es un heredero de la tradición norteamericana del género policial. Gran parte de su producción cuentística y novelística ancla en el relato de investigación: Nombre falso (1975) y su famoso "Homenaje a Roberto Arlt", Respiración artificial (1980), Prisión perpetua (1988), La ciudad ausente (1992), Plata quemada (1997) y Blanco nocturno (2010). Sus ensayos y entrevistas, Crítica y ficción (1986) y El último lector (2005) también dan cuenta del análisis de los tópicos del género.

En "La loca y el relato del crimen" la búsqueda del criminal está en manos del periodista Emilio Renzi. Esta relación entre lo policial y lo periodístico está inscrita en la misma fundación del género. En los cuentos de Poe, Dupin encuentra en los diarios ciertas claves que le ayudarán en sus pesquisas. "El misterio de Marie Rogêt", por ejemplo, es a juicio de Walter Benjamin, el prototipo de la valoración de las informaciones periodísticas en su contribución al descubrimiento del crimen. Allí, Dupin no se basa en inspecciones oculares, sino en las pistas que aparecen en las noticias de Le Commerciel.

Es que la prensa moderna nació con esa sociedad de masas donde se dejaron de lado los grandes temas ideológicos y políticos para abordar ahora cuestiones de la vida cotidiana de un público masivo. Al alero de la revolución tecnológica se empezaron a imprimir grandes tiradas, primero con relatos de aventuras y de amor, que luego derivaron a asesinatos, violencia callejera, corrupción, dramas de familia. Las historias policiales encontraron su hábitat natural en las páginas de la prensa sensacionalista, nacida con el Sun y consolidada con el Herald. La consigna era una sola: sangre en portada.

Ricardo Piglia sostiene que "(...) entre la novela de enigma y la novela dura, está el relato periodístico, las páginas de crímenes, los hechos reales" (1986: 60). Fusionando ambas dimensiones el escritor argentino crea al periodista/ detective Emilio Renzi, de quien se dan las primeras pistas en "El fin del viaje" (Piglia, 1994):

- ¿Usted en qué trabaja?

- Soy periodista.

3 La historia de la prensa tiene entre sus páginas un episodio paradigmático de la efectividad de la investigación-periodística-detectivesca: en 1975 las pesquisas de los profesionales del Washington Post, Bob Woodward y Carl Bernstein, que seguían el caso Watergate, desembocaron en la mismísima renuncia del presidente de Estados Unidos, Richard Nixon. 
- ¿Periodista? Qué maravilla. No me diga que hace policiales.

- No —dijo él一. Lamentablemente sólo hago crítica de libros.

- Es una lástima - dijo ella, divertida - Sería apasionante que por ejemplo fuera a Mar del Plata a hacer la nota de algún crimen. ¿Y cómo es hacer crítica de libros?

- Un poco monótono — dijo Emilio-.

En "La loca y el relato del crimen" (1994) Renzi continúa ganándose la vida con las bibliográficas en el diario El Mundo, a pesar de su interés por la linguiística. Su oficio tiene por tanto un aire a decadencia y frustración. Dice el narrador:

(...) haber pasado cinco años en la Facultad especializándose en la fonología de Trubetzkoi y terminar escribiendo reseñas de media página sobre el desolado panorama literario nacional era sin duda la causa de su melancolía (...) (68)

La historia del cuento transcurre en un ambiente marginal y marchito, entre las calles a orillas de río donde transitan "putas baratas y cafishios", albergue de dancings y cabarets como el pervertido New Deal. Ésa será la escena del crimen de Larry, prostituta de "piel gastada (...) altiva, borracha, indiferente". La policía culpa y apresa a Antúnez, quien vivía con la víctima en la pensión de Viamonte y Reconquista. Ésa será la noticia policial que cubrirá Renzi, un encargo de su editor, el viejo Luna, esperanzado que el cambio de sección le haga anímicamente bien.

En "Encuentro en Saint Nazaire" (Piglia, 1988) Stephen Stevensen reconoce que hay dos formas de descifrar los enigmas: la acumulación infinita de datos diferentes o la utilización infinita de un mismo dato, una partícula quizás insignificante, al que hay que seguir en su recorrido. El reportero de El Mundo adhiere al segundo método para intentar resolver el asesinato de Larry. Aquellas partículas son las palabras claves del discurso esquizofrénico de la única testigo del hecho: la loca Angélica Inés Echevarne. Renzi, en su afán detectivesco, encuentra el volátil sentido en medio del caos y la locura. Su método no es la abstracta razón, ni la infalible lógica y tampoco la lectura de textos. Su técnica es la de un saber científico aprendido en la facultad: los operadores lógicos, un código que se usa para analizar el lenguaje psicótico:

Son como un mapa, usted los pone sobre lo que dicen y se da cuenta que el delirio está ordenado, que repite esas fórmulas. Lo que no entra en ese orden, lo que no se puede clasificar, lo que sobra, el desperdicio, es lo nuevo: es lo que el loco trata de decir a pesar de la compulsión repetitiva. (...) Yo hice eso y separé esas palabras y ¿qué quedó? - dijo Renzi levantando la cara para mirar al viejo Luna-. ¿Sabe qué queda? Esta frase: El hombre gordo la esperaba en el zaguán y no me vio y le habló de dinero y brilló esa mano que la hizo morir. 
¿Se da cuenta? — remató Renzi, triunfal—. El asesino es el gordo Almada. (71)

Pero el descubrimiento de Renzi es rechazado por Luna, el editor, en un diálogo que hipercondensa el funcionamiento de la verdad periodística:

- $\quad$ Tranquilizate pibe. ¿O te pensás que este diario se dedica a la lingüística?

- Hay que publicarlo ino se da cuenta? Así lo pueden usar los abogados de Antúnez. ¿No ve que ese tipo es inocente?

- $\quad$ Oíme, el tipo ése está cocinado, no tiene abogados, es un cafishio, la mató porque a la larga siempre terminan así las cosas ésas. Me parece fenómeno el jueguito de palabras, pero paramos acá. Hacé una nota de cincuenta líneas contando que a la mina la mataron a puñaladas.

- Escuche, señor Luna - lo cortó Renzi-. Ese tipo se va a pasar lo que le queda de vida metido en cana.

- Ya sé. Pero yo hace treinta años que estoy metido en este negocio y sé una cosa: no hay que buscarse problemas con la policía. Si ellos te dicen que lo mató la Virgen María, vos escribís que lo mató la Virgen María. (71-72)

La verdad del periodista/detective es silenciada por el editor porque proviene del testimonio de quien, siguiendo a Foucault, representa el espacio que la sociedad aísla de sí misma, como su afuera contaminante. Esa versión es la de una loca que, de acuerdo a El orden del discurso, pertenece a un no-saber, a un no-orden, a un no-decir: es un "otro" por antonomasia. Y sobre el discurso de la otredad se impone el del poder, metaforizado en El Mundo, un medio de comunicación que opera sobre la base de una racionalidad, unos efectos, unos usos y una cierta configuración estratégica que lo instalan como uno más de los dispositivos del poder. El discurso delirante de Angélica Echevarne es ocluido por una institucionalidad que construye, y trata de legitimar, una verdad propia. "El poder, más que reprimir 'produce realidad', y más que ideologizar, más que abstraer u ocultar, produce verdad" (Deleuze, 1987: 55). Con eso no hay que meterse le advierten a Renzi y, menos, armar líos. Hacer lo contrario es arruinarse la vida.

Hasta aquí, el destino del cuento es la prisión de Antúnez, la inculpabilidad de Almada, la exclusión de la loca y el retorno de Renzi a su castrante rutina funcionaria. Sin embargo, Ricardo Piglia ofrece un camino de salida para la historia:

Renzi se sentó frente a la máquina y puso un papel en blanco. Iba a redactar su renuncia; iba a escribir una carta al juez (...) Después bajó la cara y se largó a escribir casi sin pensar, como si alguien le dictara:

Gordo, difuso, melancólico, el traje de filafil verde nilo flotándole en el cuerpo - empezó a escribir Renzi-, Almada salió ensayando un aire de secreta euforia para tratar de borrar su abatimiento. (72) 
Ante la imposibilidad del decir a través de la unidad de redacción tradicional del medio de comunicación informativo, la noticia, Renzi encuentra un punto de fuga: el cuento. Es que, de acuerdo a Foucault, ninguna manifestación del poder es tan comprensiva y total para no permitir la resistencia: “(...) no hay diagrama que no implique, al lado de puntos que conecta, puntos relativamente libres o liberados, puntos de creatividad, de mutación (...)" (Deleuze, 1987: 70). El reportero cuestiona el andamiaje que le imposibilita expresar su verdad, y lo intercambia por un producto literario, foráneo. Renzi, y su relato del crimen, es la mejor manera de entender que escribir es luchar, resistir; escribir es devenir; escribir es cartografiar (Deleuze, 1987).

\section{Conclusiones}

Si el detective literario es metáfora del intelectual, sujeto que reflexiona e interpreta nuestras sociedades, el género policial es la narración a través de la cual podemos comprenderlas. Los relatos de crímenes se convierten en signos lúcidos de los contextos históricos, políticos y culturales, el espejo donde se reconocen las relaciones con el dinero, la ley, la verdad, el delito, el complot o el enigma, factores que hacen realmente funcionar el sentido de una sociedad.

El análisis de "La muerte y la brújula" y de "La loca y el relato del crimen" colaboran en la compresión de las transformaciones en el perfil de ese intelectual en el ámbito latinoamericano. Las representaciones literarias del detective en esas narraciones sintonizan con lo que se ha analizado fuera del ámbito de la ficción, principalmente con La ciudad letrada de Angel Rama. Allí, el crítico uruguayo da cuenta de los rasgos que caracterizaron al pensador de las utopías de los 60, aquél que respondía a agendas culturales y políticas que proponían la verdadera fundación de una identidad local, y que basaba su programa excesivamente en el poder de gestión de la alta cultura. Se trataba de un intelectual que, miembro de una especie de cleresía, tomó el poder de la palabra en nombre de una inmensa mayoría y, amparado en los dispositivos de poder, fue el centro hegemónico de una sociedad en la que lograba imponer sus ideas e influir o incluso determinar muchas de sus dimensiones.

Rama examina también el tránsito de ese teórico al de la lógica capitalista de los 70 y 80 , un paradigma donde prima la especialización, la profesionalización, la intervención de los medios de masas y los proyectos de corto alcance a cargo de nuevos agentes que incluso habitan los extramuros de la cultura letrada. Con intenciones menos radicales y totalizantes, este nuevo actor social criticará su propia labor como creador de sentido y se abrirá a fenómenos híbridos. Es que "el intelectual ha perdido la centralidad que tenía, el privilegio de producir naciones, y se desenvuelve ahora en una práctica más horizontal, en una dinámica de oposición/negociación con la globalización” (Lecuna, 1999). 
En el contexto descrito, el cuento de Borges acaba con lo que el mismo escritor argentino llama "all-too-subtle detective", lo que transformado en virtud de este trabajo, es la desaparición del "all-too-subtle-intelectual/crítico". La narración propone la muerte del pensador total, del lector que solo vive de los signos que hay que interpretar, el semiólogo absoluto que vive atormentado de sentido y que se planta frente a los demás, el comisario Franz Trevinarus o el asesino Red Scharlach, como un hermeneuta infalible y suficiente, solitario y apartado del mundo prosaico representado por el pragmatismo de la policía o las simplificaciones del periodismo. Lönnrot se instala en una posición de poder, la del "puro razonador", y desde ella gestiona su verdad con la confianza en una capacidad reflexiva superior para comprender las complejas realidades con una nitidez y claridad únicas.

Pero algo de "tahúr" había en él. El error de Lönnrot, dice Amelia Barili, "es creerse un filósofo que ha ideado un sistema perfecto" (1999: 197). El detective de Borges no media, no transa, no constrasta sus bibliográficas hipótesis con las pedestres huellas dejadas en las escenas del crimen. Siguiendo a Kracauer, Lönnrot se queda solo en la esfera superior de la investigación, en la dimensión cerebral e intelectiva, desconociendo los aportes que puede darle lo sensitivo $\mathrm{y}$, con ello, renunciando al atributo que reconoce que el intelectual es un punto de intersección entre lo culto y lo menor.

Con la muerte del detective, "La muerte y la brújula" opera como punto de inflexión en la representación del intelectual, simbolizando el término del ciclo de su infalibilidad y suficiencia, e inaugurando otra etapa a cargo de un marginal, melancólico y presionado Emilio Renzi. El cuento de Borges deja abierta la pesquisa para que Ricardo Piglia la retome, ahora en manos de un reportero.

En efecto, Piglia perfila a su personaje como un funcionario del matutino El Mundo, metáfora del relativismo del nuevo intelectual, pues el medio de comunicación es paradigma del espacio de encuentro de incesantes versiones y verdades, del intercambio y préstamo intercultural. Renzi trabaja en el territorio de la hibridez, donde se cruzan los registros más plurales. El espacio dejado por el pensador extraordinario es ocupado ahora por una variada gama de voces (sociólogos, antropólogos, tecnócratas y especialistas en mass media) que juntas construyen la reflexión de la sociedad, ninguna de las cuales se impone sobre la otra y, menos, constituye una ruta de navegación.

La marginalidad de Renzi está representada por la sección donde trabaja, Policía, una parcela informativa distante de las temáticas centrales, Política y Economía, y nacida bajo el impulso de la sociedad de masas y sus crecientes crímenes. Esa lateralidad del detective también se detecta en el manejo de un saber, la fonología de Trubetzkoi, que lo aleja de las epistemologías clásicas, y 
lo acerca a los tipos de conocimientos contemporáneos que saben leer en los rastros que no son centrales, los signos de construcción de la verdad.

El nuevo perfil del intelectual se ficcionaliza también en el hecho que Emilio Renzi interpreta bajo amenaza. Porque si bien la ruta reflexiva que sigue Lönnrot fue ideada por Scharlach, el ejercicio del personaje de Borges es el de un hermeneuta independiente, que se moviliza por cuenta propia, según sus individuales deducciones. El periodista de El Mundo piensa en condiciones muy distintas. "No es un intérprete que funcione con el modelo del intérprete académico (...) en una situación cómoda y tranquila, conversando, sino que es un intérprete que está bajo amenaza, bajo una situación de peligro extremo, marcando bien un estado de la sociedad moderna, es decir, una tensión entre el saber y la amenaza" (Piglia, 2010). Sobre Renzi caen todos los dispositivos de poder y restricción de la institucionalidad en la que trabaja, que recurre finalmente a una de las intimidaciones clásicas: el despido. Al respecto hay que recordar las palabras de Sartre: el intelectual está sometido a las presiones de su sociedad y, por tanto, nunca es más intelectual, que cuando está rodeado, presionado, intimidado.

Otra de las características que marca la transformación del intelectual/ detective es el acceso al discurso, la capacidad de decir. Erick Lönnrot responde al perfil del intelectual clerical, que se maneja como el integrante de un grupo que tiene el privilegio del pensamiento crítico y que más que cuestionar lo establecido, adhiere a sus códigos. En la conciencia de su nitidez y clarividencia se maneja de manera central, dominante y autosuficiente. Está tan obsesionado con la lectura, que no tiene tiempo para decir, es un detective que sólo atiende a indicios textuales y que alimenta sus intuiciones con la lectura de más textos. Lönnrot hace honor a las capacidades racionales del crítico, pero no llega a ser un hombre de acción.

El problema del intelectual es que las sociedades están dominadas por hábitos de expresión que existen con anterioridad a él, y una de cuyas funciones es preservar el statu quo y asegurar que las cosas marchen sin sobresalto, sin cambios ni desafíos. Foucault lo explica: la sociedad es una espesa red compuesta por instituciones (de justicia, policiales, médicas, etc.) cuya trama impone un determinado tipo de discurso que se desplegará mediante un lenguaje que pretenderá ser el de la observación y el de la neutralidad.

Esa verdad discursiva dominante, representada en el cuento por las palabras del viejo Luna, tratará de imponerse a Renzi. Frente a la represión y a las técnicas de control, el periodista encuentra un punto de liberación, un punto de fuga: la escritura de un relato. El personaje de Piglia actúa entonces como un detective que, en tensión entre la ley la verdad, construye esta última fuera de los sistemas institucionales. Ahí está cifrado el ideal del intelectual: la 
búsqueda de lo alternativo, la contravención, el ejercicio del desacato. Emilio Renzi simboliza a quien es capaz de ofrecer resistencia a las representaciones del poder, poniendo en tela de juicio sus imágenes, sus decires y sus justificaciones.

El periodista de "La loca y el crimen" transgrede desde el mismo dispositivo del poder: el discurso. Frente a la versión del medio de comunicación (podría ser también del Estado, del género dominante, del logocentrismo, de una clase, etc.) él opone otro texto. El "Gordo, difuso, melancólico, el traje de filafil verde nilo flotándole en el cuerpo...” proclama la verdad de un hecho no expresable en términos de crónica periodística, entendida como la modalidad discursiva confortablemente asentada en el medio de comunicación social, y que impone a sus contenidos un aura de objetividad, veracidad y pluralidad. La salida literaria que encuentra Renzi responde al intelectual ideal propuesto por Said: “(...) individuo dotado de la facultad de representar, encarnar y articular un mensaje, una visión, una actitud, una filosofía, una opinión para y a favor de un público (...) alguien a quien ni los gobiernos ni otras instituciones pueden domesticar fácilmente".

Renzi encuentra en el relato, en la literatura, el refugio de la verdad. Dice Foucault: “(...) la literatura tendrá que colocarse ella misma fuera de la ley, o al menos hacer recaer sobre ella la carga del escándalo, de la transgresión, o de la revuelta. A ella le corresponde decir lo más indecible, lo peor, lo más secreto, lo más intolerable, lo desvergonzado" (Foucault, 1996: 137).

"La loca y el relato del crimen" es, por tanto, la forma que tiene Piglia de decir que la verdad de la sociedad, aquella que el intelectual está llamado a proclamar, se agazapa en la ficción: "Narrar, decía mi padre, es como jugar al póker, todo el secreto consiste en parecer mentiroso cuando se está diciendo la verdad" (Piglia, 1988: 22). El intelectual puede encontrar entonces en el relato de ficción la unidad textual para hablarle al poder, pues cualquier discurso reflexivo autoral cabe en una narración ficticia, "a condición de que parezcan falsos. Esa ilusión de falsedad, dijo Renzi, es la literatura misma”. Ricardo Piglia figura al intelectual que puede decir la verdad, potencia principal del crítico de todas las épocas.

\section{Referencias bibliográficas}

BARILI, A. (1999) Jorge Luis Borges y Alfonso Reyes: la cuestión de la identidad del escritor latinoamericano. México D.F.: Fondo de Cultura Económica.

BOCCARDI, F. G. (2008) "Semiología y Hermenéutica: anotaciones para pensar el sentido desde la literatura policial y el psicoanálisis”. Alpha $N^{\circ} 27$ (U. de los Lagos, Chile): pp. 209-216.

BORGES, J. L.(1997) Borges oral, Obras completas, tomo IV. Buenos Aires: Emecé. 
BORGES, J.L.(2008) Ficciones. Barcelona: Emecé.

DELEUZE, G. (1987) Foucault. Buenos Aires: Paidós.

FOUCAULT, M. (1996) La vida de los hombres infames. La Plata: Altamira.

FOUCAULT, M. (2008) Vigilar y castigar. Nacimiento de la prisión. Buenos aires: Siglo XXI.

KRACAUER, S (2010) La novela policial. Un tratado filosófico. Buenos Aires: Paidós.

LECUNA, V. (1999) La ciudad letrada en el planeta electrónico. Pliegos: Madrid.

LINK, D. (2003) El juego de los cautos. Buenos Aires: La Marca editora.

NARCEJAC, T. (1970) La novela criminal. Barcelona: Tusquets.

PARODI, C. (2011) “Borges y la subversión”. Obtenido de Borges Center de la Universidad de Pittsburg: http://www.borges.pitt.edu

PIGLIA, R. (1986) Crítica y ficción. Barcelona: Anagrama.

PIGLIA, R. (1988) Prisión perpetua. Barcelona: Anagrama.

PIGLIA, R.(1994) Nombre falso. Buenos Aires: Seix Barral.

PIGLIA, R.(2005a) El último lector. Barcelona: Anagrama.

PIGLIA, R. (2005b) Formas breves. Barcelona: Anagrama.

PIGLIA, R (2010) “Poe y Borges”. Obtenido de http://www.elhilodeariadna.org

SAID, E. (2007) Representaciones del intelectual. Madrid: Debate.

SARLO, B. (2007) Borges, un escritor en las orillas. México D.F.: Siglo Veintiuno Editores.

TODOROV, T. (1996). Los géneros del discurso. Caracas: Monteávila editores. 
